\title{
ANALISIS SWOT DALAM MENETAPKAN STRATEGI MENJALANKAN BPJS KESEHATAN PADA MITRA KELUARGA KALIDERES
}

\author{
Martinus Limaku \\ Program Studi Magister Manajemen Universitas Tarumanagara
}

\begin{abstract}
This study aims to analyze and determine the best strategy for Mitra Keluarga to be ready to join BPJS Kesehatan. Mitra Keluarga is a place that provides health services. This study used a SWOT analysis to get the best strategy for Family Partners. Data sources come from hospital managerial officers and from government regulations. The SWOT analysis is used to get the best strategy for Mitra Keluarga to find out what are the strengths, weaknesses, opportunities and threats of the company. Alternative strategies will be analyzed with everything that happens in the hospital or from outside the hospital. The conclusion of this study is to implement a strategy in running the Health BPJS on the Kalideres Family Partner in accordance with the company's external and internal conditions.
\end{abstract}

Abstrak : Penelitian ini bertujuan untuk menganalisis dan menentukan strategi terbaik bagi Mitra Keluarga untuk siap bergabung dengan BPJS Kesehatan. Penelitian ini menggunakan analisis SWOT untuk mendapatkan strategi terbaik untuk Mitra Keluarga. Sumber data berasal dari petugas manajerial rumah sakit dan dari aturan pemerintah. Analisis SWOT digunakan untuk mendapatkan strategi terbaik bagi Mitra Keluarga untuk mengetahui apa saja kekuatan, kelemahan, peluang dan ancaman dari perusahaannya. Strategi alternatif akan dianalisis dengan semua hal yang terjadi di rumah sakit atau dari luar rumah sakit. Kesimpulan dari penelitian ini adalah untuk menerapkan strategi dalam menjalankan BPJS Kesehatan pada Mitra Keluarga Kalideres sesuai dengan kondisi eksternal dan internal perusahaan.

\section{Kata Kunci : Strategi, SWOT Matrix, MITRA KELUARGA, BPJS}

\section{Pendahuluan}

Badan Pengelola Jaminan Sosial Kesehatan atau yang lebih dikenal dengan BPJS Kesehatan, digulirkan oleh Pemerintah sejak tanggal 1 Januari 2014, merupakan program Jaminan Kesehatan Nasional (JKN), sesuai dengan visi BPJS diharapkan pada tanggal 1 Januari 2019 seluruh masyarakat Indonesia harus menjadi peserta BPJS Kesehatan. Sesuai Perpres No. 82 Tahun 2018 mewajibkan pendaftaran ke BPJS Kesehatan paling lambat tanggal 1 Januari 2019 bagi peserta mandiri, dengan kata lain, warga yang belum didaftarkan oleh perusahaan atau badan usaha tempatnya bekerja dan warga bukan penerima bantuan iuran. Adapun sanksi bagi warga yang belum mendaftar tertuang dalam PP No. 86 Tahun 2013, yakni sanksi administratif berupa teguran tertulis, denda, atau tidak mendapatkan pelayanan publik tertentu.

Sehingga banyak perusahaan yang selama ini memberikan pelayanan kesehatan bagi karyawannya dengan jaminan perusahaan atau asuransi komersil, beralih ke BPJS Kesehatan. Dikarenakan Mitra Keluarga belum bekerjasama dengan BPJS Kesehatan maka tidak bisa melayani peserta BPJS Kesehatan kecuali dalam keadaan darurat (emergency).

Kondisi diatas berdampak ke pendapatan emiten PT Mitra Keluarga Karyasehat Tbk. pada tahun 2017 naik hanya 2,46\%. Pada tahun 2017 pendapatan emiten berkode MIKA itu senilai Rp 2,49 triliun. Adapun pada tahun 2016 pendapatan MIKA mencapai Rp 2,43 triliun. Hal ini menunjukan bahwa BPJS Kesehatan berpengaruh terhadap pendapatan. Oleh karena itu, dibutuhkan penyesuaian strategi untuk menghadapi berlakunya BPJS Kesehatan. 


\begin{tabular}{|c|c|c|c|c|c|c|}
\hline \multicolumn{5}{|c|}{$\begin{array}{l}\text { Laporan Laba Rugi Komprehensif Konsolidasian } \\
\text { Consolidated Statements of Comprehensive Income }\end{array}$} & \multicolumn{2}{|c|}{$\begin{array}{l}\text { Dalam jutasn Rupiah kecuali inyatiosan lair } \\
\text { In milition of Rupiah, uniess otherwise statec }\end{array}$} \\
\hline & 2018 & 2017 & 2016 & 2015 & 2014 & \\
\hline Pendapatan & $2,713,087$ & $2,495,712$ & $2,435,466$ & $2,140,704$ & $1,945,508$ & Revenues \\
\hline Laba Bruto & 1.284 .302 & $1,185,524$ & $1,155,799$ & 972,307 & 864,588 & Gross Profit \\
\hline Laba Usaha & 780,326 & 759.758 & 745,720 & 604,920 & 588.922 & $\begin{array}{l}\text { Income from } \\
\text { Operations }\end{array}$ \\
\hline $\begin{array}{l}\text { Laba Sebelum Beban Pajak } \\
\text { Penghasilan }\end{array}$ & 850,148 & 877.155 & 896.310 & 739,777 & 669.397 & $\begin{array}{l}\text { Income before income } \\
\text { Tax Expense }\end{array}$ \\
\hline Laba Tahun Berjalan & 658,737 & 708,762 & 720,721 & 588,447 & 536,207 & Income for the Year \\
\hline \multicolumn{7}{|l|}{$\begin{array}{l}\text { Laba Tahun Berjalan yang } \\
\text { Dapat Diatribusikan Kepada }\end{array}$} \\
\hline Pemilik entitas induk & 613,559 & 679,808 & 695,439 & 566,820 & 518,828 & $\begin{array}{r}\text { Equity holders of the } \\
\text { parent entily }\end{array}$ \\
\hline $\begin{array}{l}\text { Kepentingan non- } \\
\text { pengendali }\end{array}$ & 45,178 & 28,954 & 25,282 & 21,627 & 17.379 & $\begin{array}{r}\text { Nan-controlling } \\
\text { interests }\end{array}$ \\
\hline Jumlah & 658,737 & 708,762 & 720,721 & 588,447 & 536.207 & $\begin{array}{l}\text { Comprehensive } \\
\text { Income for the Year }\end{array}$ \\
\hline \multicolumn{7}{|l|}{$\begin{array}{l}\text { Jumlah Laba Komprehensif } \\
\text { Tahun Berjalan yang Dapat } \\
\text { Daatirbuskikan Kepada }\end{array}$} \\
\hline Pemilik entitas induk & 701,069 & 669,119 & 696,559 & 570,492 & 525,408 & $\begin{array}{l}\text { Equity holders of the } \\
\text { parent entity }\end{array}$ \\
\hline $\begin{array}{l}\text { Kepentingan non- } \\
\text { pengendali }\end{array}$ & 51,407 & 27,871 & 24.648 & 22,381 & 17,985 & $\begin{array}{r}\text { Non-controlling } \\
\text { interests }\end{array}$ \\
\hline Jumlah & 752,476 & 696,990 & 721,206 & 592,873 & 543,393 & Total \\
\hline $\begin{array}{l}\text { Laba per Saham Dasar yang } \\
\text { Dapat Diatribusikan Kepada } \\
\text { Pemilik Entitas Induk (Rp) }\end{array}$ & 42 & 47 & 48 & 39 & 38 & $\begin{array}{l}\text { Basic Earnings per } \\
\text { Share Attributable to } \\
\text { Equity Hoiders of The } \\
\text { Parent Entity (Rp) }\end{array}$ \\
\hline
\end{tabular}

\section{Tujuan Penelitian}

Tujuan Penelitian ini adalah untuk menyusun strategi menjalankan BPJS Kesehatan pada Mitra Keluarga Kalideres. Sedangkan ruang lingkup penelitian ini difokuskan pada formulasi strategi Mitra Keluarga dengan mengidentifikasikan faktor-faktor internal rumah sakit dan eksternal rumah sakit yang dapat meningkatkan proses bisnis yang ada di Mitra Keluarga dengan menggunakan Analisa SWOT.

\section{Tinjauan Pustaka}

Menurut David (2009:327) Konsep matriks SWOT merupakan perangkat pencocokan yang penting untuk membantu manajer mengembangkan empat tipe strategi SO WO-ST-WT. Strategi SO atau strategi kekuatan-peluang menggunakan kekuatan internal perusahaan untuk memanfaatkan peluang eksternal. Jika perusahaan mempunyai kelemahan besar, perusahaan akan berusaha keras untuk mengatasinya dan membuatnya menjadi kekuatan. Kalau menghadapi ancaman besar, sebuah organisasi akan berusaha menghindarinya agar dapat memusatkan perhatian pada peluang.

Menurut Florentina Melani (2017) pada penelitian sebelumnya tentang SWOT Analysis on BPJS/JKN Implementation in Ngaliyan Health Center Semarang, penelitian dilakukan pada Faskes Pertama Ngaliyan Health Center di Semarang, peneliti menggunakan analisa SWOT untuk menentukan implementasi BPJS/JKN dengan hasil yang ditemukan sebagai berikut: bahwa implementasi dari Program BPJS/JKN di Ngaliyan Health Center telah dilakukan sebaik mungkin dimana ada beberapa titik kritis dalam hal pembelajaran ketika ada defisit dalam implementasi layanan kesehatan. Saran alternatif yang peneliti berikan adalah meningkatkan kinerja pelayanan, dimana bila kinerja ditingkatkan maka dana kapitasi pun akan besar.

Berdasarkan kajian dari penelitian yang dilakukan oleh Florentina Melani dan Theresia Tatie Marsriri (2017) dapat disimpulkan bahwa pentingnya kerjasama tim dan dukungan dari para stakeholder dalam memberikan pelayanan terhadap pasien BPJS/JKN sehingga dengan demikian kendali mutu dan kendali biaya dapat dilakukan lebih maksimal lagi, disamping itu 
image perusahaan pun akan semakin meningkat dikalangan masyarakat sekitar dan akan mampu memberikan tambahan value dan peningkatan sales kedepannya. Manajemen Rumah Sakit Umum Surya Husadha Ubung saat ini sedang mengupayakan usaha membangun juga image dimata masyarakat dengan melakukan perbaikan di lingkungan internal dan senantiasa memperhatikan masukan dan saran dari lingkungan eksternal

\section{Metodologi Penelitian}

Evaluasi strategi yang digunakan dalam penelitian ini adalah dengan matriks SWOT yaitu dengan berdasarkan Analisa SWOT. Matriks ini memaparkan strategi-strategi secara umum yang dapat digunakan oleh Mitra Keluarga untuk menerapkan strategi tersebut dalam proses bisni rumah sakit, dengan jalan memanfaatkan kekuatan dan peluang serta meminimalisasi kelemahan dan ancaman terhadap Mitra Keluarga.

Dalam penyusunan penelitian ini, data yang digunakan adalah data primer dan data sekunder. Berikut penjelasan jenis data yang digunakan dan teknik pengumpulan datanya :

1. Data Primer

Data primer merupakan data yang diperoleh langsung dari sumber data, dengan cara melakukan riset langsung ke lapangan dan mendatangi Mitra Keluarga Kalideres sebagai objek penelitian guna mendapatkan data-data melalui :

a. Studi lapangan

Studi lapangan dilakukan dengan mendatangi Mitra Keluarga Kalideres unttuk memenuhi kebutuhan data pokok penyusunan penelitian.

b. Pengamatan (Observasi)

Tujuan observasi untuk memperoleh gambaran yang tepat mengenai keadaan dan aktivitas-aktivitas yang dilakukan oleh perusahaan.

c. Wawancara

Wawancara dilakukan dengan melakukan tanya jawab dengan Direktur Mitra Keluarga Kalideres yaitu dr Reinette Meiske Eve, MARS mengenai informasi yang berkaitan dengan penetapan strategi menjalankan BPJS Kesehatan pada Mitra Keluarga Kalideres

2. Data Sekunder

Data sekunder merupakan data yang diambil dengan cara mengumpulkan data dari arsiparsip dan catatan-catatan didalam perusahaan yang diperlukan untuk menunjang penelitian, antara lain data mengenai : profil, gambaran dan struktur organisasi Mitra Keluarga Kalideres

\section{Hasil dan Kesimpulan}

Dari hasil penelitian, diketahui bahwa yang menjadi :

1. Kekuatan dari Mitra Keluarga Kalideres yaitu pengenalan nama "MITRA KELUARGA" sudah dikenal oleh masyarakat, akreditasi KARS paripurna, fasilitas ruangan yang lengkap, peralatan penunjang medis yang lengkap

2. Kelemahan dari Mitra Keluarga Kalideres yaitu lokasi rumah sakit yang jauh dari jalan utama dan biaya prawatan yang mahal,

3. Peluang bagi Mitra Keluarga Kalideres yaitu kesadaran masyarakan akan pentingnya kesehatan

4. Ancaman bagi Mitra Keluarga Kalideres yaitu banyak rumah sakit competitor sekitar Mitra Keluarga Kalideres, peraturan pemerintah yang mewajibkan ikut BPJS Kesehatan, masyarakat yan semakin kritis dengan mutu pelayanan kesehatan.

Dari hasil analisa yang dilakukan di Mitra Keluarga Kalideres, dapat disimpulkan bahwa dari hasil analisa faktor internal dan ekstemal Mitra Keluarga Kalideres didapatkan bahwa pemasaran/promosi Mitra Keluarga Kalideres serta perbaikan manajemen rumah sakit diperlukan dan merupakan faktor paling panting yang harus dibenahi lebih dulu oleh Mitra Keluarga Kalideres. Jika dilihat dari strategi Mitra Keluarga Kalideres, yang paling menarik 
untuk dilakukan adalah strategi promosi, dari strategi S-O karena Mitra Keluarga Kalideres pada merupakan bisnis yang bcrgerak dibidang jasa sehingga promosi baik media cetak, media elektronik maupun promosi langsung melalui seminar awam adalah cara paling baik untuk menghadapi persaingan saat ini.

\section{Tabel 5.1 Matrix TOWS MITRA KELUARGA KALIDERES}

\begin{tabular}{|c|c|c|}
\hline & $\begin{array}{l}\text { Strength: } \\
\text { 1. Pengenalan nama "MITRA KELUARGA" } \\
\text { telah banyak dikenal masyarakat } \\
\text { 2. RS terbaik ke-1 di Indonesia (sumber : } \\
\text { webometrics hospital) } \\
\text { 3. Akreditasi KARS paripurna } \\
\text { 4. Sumber daya manusia yang berkualitas dan } \\
\text { berkompeten di bidangnya (dokter, perawat, } \\
\text { apoteker, radiographer, analis medis dan lain } \\
\text { sebagainya) } \\
\text { 5. Fasilitas ruangan Mitra Keluarga Kalideres } \\
\text { yang cukup lengkap (ICU, IMC, OK, PERINA, } \\
\text { NICU, dan lain sebagainya) } \\
\text { 6. Kelengkapan peralatan penunjang medis } \\
\text { yang lengkap (MRI 1.5 Tesla, Angio, CT Scan, } \\
\text { Laboratorium lengkap, Endoscopy, dan lain } \\
\text { sebagainya) } \\
\text { 7. Spesialisasi dokter yang lengkap }\end{array}$ & $\begin{array}{l}\text { Weaknesses: } \\
\text { 1. Lokasi rumah sakit yang jauh dari akses } \\
\text { jalan utama. Akses dari perumahan warga } \\
\text { ke rumah sakit harus melewati jalan yang } \\
\text { macet untuk sampai ke Mitra Keluarga } \\
\text { Kalideres. } \\
\text { 2. Biaya perawatan yang tinggi } \\
\text { 3. Turn over tenaga kesehatan cukup } \\
\text { tinggi, khususnya bagian keperawatan } \\
\text { 4. Komunikasi dan koordinasi yang lemah }\end{array}$ \\
\hline Oppo & & \\
\hline $\begin{array}{l}\text { 1. Pertumbuhan ekonomi masyarakat yang } \\
\text { signifikan }\end{array}$ & $\begin{array}{l}\text { 1. Mengenalkan kepada masyarakat sekitar } \\
\text { Mitra Keluarga Kalideres mengenai produk } \\
\text { unggulannya melalui media cetak, banner, } \\
\text { billboard ataupun seminar awam } \\
\text { 2. Melakukan pendekatan dan pengenalan }\end{array}$ & $\begin{array}{l}\text { 1. Memberikan akses layanan transportasi } \\
\text { menuju Mitra Keluarga Kalideres, baik } \\
\text { penjemputan dirumah dengan } \\
\text { menggunakan ambulance atau menunggu } \\
\text { ditempat-tempat yang sudah ditentukan }\end{array}$ \\
\hline 2. Banyak usia produktif di daerah kalideres & $\begin{array}{l}\text { layanan rumah sakit kepada perusahaan target } \\
\text { pemasaran }\end{array}$ & \\
\hline $\begin{array}{l}\text { 3. Semakin sadarnya masyarakat akan } \\
\text { pentingnya asuransi khususnya bidang } \\
\text { kesehatan baik asuransi milik pemerintah atau } \\
\text { swasta } \\
\text { 4. Kesadaran masyarakat akan pentingnya } \\
\text { kesehatan dan kesadaran untuk mendapatkan } \\
\text { pelayanan kesehatan yang lebih memadai. }\end{array}$ & $\begin{array}{l}\text { 3. Menawarkan paket-paket kesehatan } \\
\text { sehubungan dengan promosi kesehatan, } \\
\text { pencegahan penyakit dan diagnosa awal kepada } \\
\text { masyarakat }\end{array}$ & \\
\hline $\begin{array}{l}\text { Threats: } \\
\text { 1. Banyak rumah sakit kompetitor di sekitaran } \\
\text { Mitra Keluarga Kalideres yang membidik } \\
\text { market yang sama } \\
\text { 2. Adanya peraturan pemerintah yang } \\
\text { mengharuskan seluruh pusat pelayanan } \\
\text { kesehatan wajib ikut bekerja sama dengan } \\
\text { BPJS KESEHATAN. } \\
\text { 3. Rendahnya tarif BPJS KESEHATAN } \\
\text { dibandingkan dengan tarif Mitra Keluarga } \\
\text { Kalideres. } \\
\text { 4. Masyarakat yang semakin kritis dengan } \\
\text { mutu pelayanan }\end{array}$ & $\begin{array}{l}\text { 1. Memilih pemasok yang memberikan } \\
\text { penawaran yang lebih efisien dan } \\
\text { menguntungkan } \\
\text { 2. Menyusun tarif yang bersaing dengan rumah } \\
\text { sakit kompetitor } \\
\text { 3. membuat clinical pathway untuk } 10 \text { penyakit } \\
\text { terbanyak }\end{array}$ & \\
\hline
\end{tabular}




\section{Daftar Pustaka}

Landasan Hukum Tentang BPJS Kesehatan, No.59 (2014)

Peraturan Presiden No.82 Tahun 2018 tentang jaminan kesehatan

PP No. 86 Tahun 2013 Tentang Tata Cara Pengenaan Sanksi Administratif Kepada Pemberi

Kerja Selain Penyelenggara Negara Dan Setiap Orang, Selain Pemberi Kerja, Pekerja, Dan Penerima Bantuan Iuran Dalam Penyelenggaraan Jaminan Sosial

Iskha Puspa Ayu Wardani. (2016). Formulasi Strategi Rumah Sakit Mayapada Melalui Pendekatan Analisis SWOT Untuk Menghadapi Diberlakukannya BPJS Kesehatan.

David, Fred R., 2004. Manajemen Strategi: Konsep-Konsep, Edisi Kesembilan, PT. Indeks, Jakarta.

David, Fred R., 2009. Manajemen Strategis Konsep, Edisi 12, Salemba Empat, Jakarta.

https://www.mitrakeluarga.com

https://www.idx.co.id/StaticData/NewsAndAnnouncement/ANNOUNCEMENTSTOCK/Fro m_EREP/201804/66fcd8cb95_5c27af2455.pdf

\section{Journal}

Florentina Melani Tahun 2016 : Analisis SWOT tentang Implementasi JKN di NgPusat Kesehatan aliyan Semarang 